\title{
A influência da Escola de Chicago na produção científica nacional em Ciência da Informação
}

\author{
The Chicago School's influence in national scientific \\ production regarding Information Science
}

\author{
Keitty Rodrigues VIEIRA' (D) 0000-0001-8649-0765 \\ Cezar KARPINSKI' (D) 0000-0003-2446-0653
}

\section{Resumo}

Denomina-se "Escola de Chicago" o movimento intelectual constituído no Departamento de Sociologia da Universidade de Chicago entre os anos 1920 e 1930 e que se estendeu também à Biblioteconomia. Nessa área, fizeram parte do movimento autores como Lee Pierce Butler, Jesse Hauk Shera e Lester Eugene Asheim, que defenderam uma epistemologia pragmatista como fundamento da Biblioteconomia. Esta perspectiva deixou como legado uma prática humanística no fazer biblioteconômico que, em útima instância, influenciou também a constituição epistemológica da Ciência da Informação. Nesse sentido, este artigo apresenta resultados de uma pesquisa cujo objetivo geral foi o de identificar a influência da Escola de Chicago na produção científica nacional em Ciência da Informação. Especificamente, os objetivos foram: verificar, por meio da Classificação JITA, em quais subáreas da Ciência da Informação os autores brasileiros mais utilizam os recursos teórico-metodológicos da Escola de Chicago e refletir sobre as contribuições do movimento da Escola de Chicago nas publicações encontradas. Metodologicamente, a pesquisa foi qualitativa e exploratória, do tipo bibliográfica, sem delimitação cronológica e organizada em três bases de dados. Como resultado, apresenta-se um corpus documental de 25 artigos, dos quais a maioria foi publicada entre 2003 e 2018 e em revistas Qualis A1, A2 e B1. Conclui-se que a influência da Escola de Chicago na produção científica da área da Ciência da Informação no Brasil dá-se no âmbito teórico, e não no prático, como sugere a vertente pragmatista que norteia o próprio movimento.

Palavras-chave: Epistemologia da Ciência da Informação. Escolas e correntes filosóficas. Pragmatismo.

\begin{abstract}
The "Chicago School" is an intellectual movement constituted in the Department of Sociology of the University of Chicago between 1920 and 1930 and that also extended to Librarianship. In this area, authors such as Lee Pierce Butler, Jesse Hauk Shera, and Lester Eugene Asheim have advocated a pragmatist epistemology as the foundation of Librarianship. This perspective left a legacy of humanistic practice within librarianship that ultimately influenced the epistemological constitution of Information Science. In this sense, this

1 Universidade Federal de Santa Catarina, Centro de Ciências da Educação, Curso de Pós-Graduação em Ciência da Informação. Campus Professor João David Ferreira Lima, s/n., Bloco B, Sala 105, Trindade, 88040-900, Florianópolis, SC, Brasil. Correspondência para/Correspondence to: C. KARPINSKI. E-mail: $<$ cezark@hotmail.com>.

Artigo elaborado a partir da dissertação de K. R. VIEIRA, intitulada "As contribuições da Escola de Chicago para a Ciência da Informação". Universidade Federal de Santa Catarina, 2019.

Apoio: Coordenação de Aperfeiçoamento de Pessoal de Nível Superior.

Recebido em 19 de março de 2019, reapresentado em 20 de novembro de 2019, aprovado em 3 de janeiro de 2020.
\end{abstract}

Como citar este artigo/How to cite this article

Vieira, K. R.; Karpinski, C. A influência da Escola de Chicago na produção científica nacional em Ciência da Informação. Transinformação, v. 32, e190037, 2020. Doi: http://dx.doi.org/10.1590/1678-9865202032e190037 
article presents the results of a research whose general objective was to identify the Chicago School's influence in the national scientific production within Information Science. Specifically, the objectives were to verify through the JITA Classification in which sub-areas of Information Science the Brazilian authors most use the theoretical-methodological resources of the Chicago School and to reflect on this school's contributions in the publications found. Methodologically, the research was bibliographic, qualitative, and exploratory, without chronological delimitation, and in three databases. As a result, a documentary corpus of 25 articles is presented, most of which were published between 2003 and 2018 in Qualis A1, A2, and B1 journals. We conclude that the influence of Chicago School in the scientific production of Information Science in Brazil occurs within the theoretical and not the practical realm, as suggested by the pragmatism aspect that guides the movement itself.

Keywords: Epistemology of Information Science. Philosophical schools and currents. Pragmatism.

\section{Introdução}

A Escola de Chicago foi um movimento acadêmico-científico de caráter pragmatista que abrangeu, em grande parte, disciplinas das áreas de Ciências Humanas e Sociais no decorrer do século XX, cujas influências são percebidas ainda hoje. O movimento constituiu-se a partir da década de 1920 no Departamento de Sociologia da Universidade de Chicago e se irradiou para outras áreas do conhecimento como, por exemplo, Arquitetura, Economia e Biblioteconomia. Sua principal característica é o fomento de pesquisas voltadas à solução de problemas sociais, pautada no pragmatismo de John Dewey e no marxismo da Escola de Frankfurt.

Na Biblioteconomia e na Ciência da Informação $(\mathrm{Cl})$, alguns autores já evidenciaram a influência do movimento na constituição epistemológica das duas áreas, como Figueiredo (1983) que associa os estudos de comunidade da Escola de Chicago aos atuais estudos de usuários da Ciência da Informação; Guimarães (2008) que relaciona o movimento com a criação dos catálogos de assunto; e Carvalho Silva (2013) que aponta a tentativa de estabelecer uma Biblioteconomia científica por parte dos autores desta perspectiva teórica, Além disso, Santos e Rodrigues (2014, p. 93) comentam que "é a percepção estadunidense que vigora em grande parte das explanações conceituais da Ciência da Informação", o que também impulsiona o desenvolvimento de pesquisas que considerem os estudos norte-americanos a partir da discussão histórica.

Contudo, um levantamento inicial permitiu concluir que não há, na literatura científica brasileira da área de Ciência da Informação, pesquisas que descrevam ou relatem especificamente como se dá/deu a influência da Escola de Chicago na referida área do conhecimento. Sendo assim, para este artigo questiona-se: "qual a influência da Escola de Chicago na produção científica brasileira em Ciência da Informação?". Para a pesquisa que visou responder a esse questionamento, estabeleceu-se, como objetivo geral, identificar publicações na área da Ciência da Informação que versem sobre autores e/ou temas relacionados à Escola de Chicago na produção científica brasileira. Especificamente os objetivos foram verificar em quais subáreas da Ciência da Informação os autores brasileiros mais utilizam os recursos teórico-metodológicos da Escola de Chicago e refletir sobre a influência das contribuições do movimento da Escola de Chicago nas publicações encontradas.

A temática escolhida justifica-se pela relação entre o movimento estudado e o fazer social que acompanha a Ciência da Informação e a Biblioteconomia, conforme abordam Ortega y Gasset (1967), Saracevic (1996) e Lankes (2013). Além disso, é uma continuação de estudos como os de Araújo et al. (2010), Araújo (2013), Vieira e Karpinski (2018a, 2018b) e Vieira e Lucas (2018).

Pesquisas como esta também se pautam nos estudos epistemológicos da área da Ciência da Informação, uma vez que o movimento intelectual da Escola de Chicago possui, como base epistemológica, o pragmatismo. Nesta perspectiva, Francelin (2018) comenta que pesquisas sobre epistemologia a partir da Ciência da Informação colaboram para a identificação de correntes teóricas, além de explicitar os autores que tratam desta temática na literatura científica nacional da área.

Corroborando com a afirmação de Matos (2012, p. 21) de que "compreender como o conhecimento de uma área do saber se estrutura, se organiza e se transforma é condição crucial para o seu aperfeiçoamento", 
entende-se que estudos como este beneficiam o avanço dos estudos históricos e epistemológicos na área de Ciência da Informação. Ademais, pesquisar sobre o movimento da Escola de Chicago, considerado um dos mais influentes na constituição de vertente humanística da Biblioteconomia, e que, posteriormente, influencia a Ciência da Informação, contribui para o desenvolvimento de novos conhecimentos a partir dos resultados obtidos e, com isso, permite uma ampliação e um aprofundamento das discussões teóricas da área.

\section{A Escola de Chicago}

O movimento intelectual denominado "Escola de Chicago", na Biblioteconomia, é uma variante da Escola Sociológica de Chicago. Para Vieira e Karpinski (2018b, p. 402) “Escola Sociológica de Chicago é o nome dado ao movimento epistemológico, acadêmico e político desencadeado por um grupo de professores e pesquisadores que, em algum momento, exerceram suas atividades na Universidade de Chicago".

As primeiras iniciativas relacionadas ao movimento surgem no Departamento de Sociologia da referida instituição, mas as atividades deste grupo de pesquisadores não se restringem a este único departamento. Sendo assim, é possível afirmar que há várias "Escolas de Chicago", as quais, conforme Eufrasio (1995) possuíam características próprias e não necessariamente atuavam da mesma forma. Assim, é possível explanar/pesquisar sobre a Escola de Chicago de Filosofia, de Sociologia, de Arquitetura, de Economia e, também, de Biblioteconomia.

A Biblioteconomia norte-americana foi diretamente influenciada pelo movimento, uma vez que o primeiro Doutorado da área foi criado pela Universidade de Chicago, o Graduate Library School, fundado em 1928. Por este passaram profissionais como Lee Pierce Butler, que defendeu a consolidação da Biblioteconomia como uma ciência a partir da obra "Introdução a Ciência da Biblioteconomia" (Butler, 1971) originalmente publicada em 1931; Lester Eugene Asheim (1954) que investigou a "censura" nas bibliotecas, instaurando uma discussão política e social ao que se chama hoje de "desenvolvimento de coleções", a partir de sua obra clássica "Not censorship, but selection"; e Jesse Hauk Shera (Shera, 1977) que propõe a disciplina de Epistemologia Social como fundamento epistemológico para a Biblioteconomia e que serve ainda hoje de parâmetros para discussões na Ciência da Informação.

Shera (1977, p. 11) entende a Epistemologia Social como "uma disciplina epistemológica, um corpo de conhecimento sobre o próprio conhecimento" e que deveria "fornecer uma estrutura para a investigação eficiente de todo o complexo problema dos processos intelectuais das sociedades". Com isso, esta nova disciplina discute a produção, o fluxo e o consumo dessas "formas de pensamento comunicado" que podem ser vistas como a própria informação, a partir de um debate teórico que vislumbra um fim aplicado, fazendo jus ao pragmatismo da Escola de Chicago.

Os trabalhos de Butler, de Shera e de Asheim tiveram como base teórica algumas abordagens oriundas da Escola Sociológica de Chicago, dentre as quais se destacam o pragmatismo de John Dewey, os estudos sobre o método sociológico de Émile Durkheim e o marxismo da Escola de Frankfurt, especialmente com as teorias de Theodor Adorno e Max Horkheimer. Por isso, uma breve compreensão sobre estes três pilares que fundamentam o movimento da Escola Sociológica de Chicago é necessário, uma vez que, para verificar a influência do movimento na Ciência da Informação atual, é preciso reconhecer o contexto das principais teorias envolvidas nesse processo epistemológico.

John Dewey, filósofo e pedagogo norte-americano, pode ser considerado como um dos criadores do Pragmatismo que serviu como base teórica para a Escola de Chicago (Silva, 2016). Dewey fez parte do corpo docente da Universidade de Chicago e, entre os anos de 1894 e 1904, fundou uma Escola Experimental vinculada ao departamento de Pedagogia da instituição, onde desenvolveu sua abordagem pragmatista (Westbrook; Teixeira, 2010). Além disso, pela Universidade de Michigan, Dewey foi professor de Robert Park, um dos principais docentes do Departamento de Sociologia, e que fez parte da chamada "primeira geração" da Escola Sociológica de Chicago. Isso evidencia, portanto, a relação entre a abordagem pragmatista de John Dewey com o movimento em questão. 
O pragmatismo enquanto corrente de pensamento e ação filosófica e científica surge no final do século XIX, inicialmente com Charles Sanders Peirce em seguida, é aprimorado por William James; e, por fim, é popularizado pela Escola de Chicago a partir dos estudos de John Dewey.

Em linhas gerais, é possível dizer que:

\begin{abstract}
Peirce entendia a experiência (experience) como 'experimento (experiment)', ou seja, como prática de laboratório, onde os procedimentos aos quais se quer dar atenção são adrede preparados, controlados e postos sob alta condição de verificabilidade. James considerou a noção de experiência de um ponto de vista, digamos, mais psicológico. Ele não desprezava a maneira pela qual Peirce, como 'homem de laboratório', via a experiência, mas trouxe o termo para perto da noção de 'vivência'. John Dewey, por sua vez, observando seus dois antecessores, procurou dissertar sobre o termo experiência de modo a torná-lo mais amplo e útil. Dewey reconduziu o termo a seu campo primordial, o da prática social (Ghiraldelli Junior, 2007, p. 16).
\end{abstract}

O movimento da Escola de Chicago baseou-se, em grande medida, nas concepções de Dewey. Por isso, pode-se dizer que o "seu" pragmatismo considera o meio social como um todo, além das experiências individuais, para a realização de estudos que resultam em produtos e serviços de utilidade social. A importância dada ao ambiente social como um fator determinante na vida do indivíduo possui relação com o legado durkheimiano, também presente nas bases que constituem o movimento da Escola de Chicago.

Nesse sentido, é importante ressaltar que a influência de Émile Durkheim deu-se de maneira explícita na produção intelectual da Escola de Chicago. É possível identificar, por exemplo, que a determinação do fator social evidenciado por Shera (1977) assemelha-se à discussão da condicionante social na vida do indivíduo, defendida por Durkheim.

Além disso, Becker (1996) considerado membro da "terceira geração" da Escola Sociológica de Chicago, afirma que o trabalho de Durkheim serviu de referência para os estudos de Robert Park, docente do Departamento de Sociologia da Universidade de Chicago. Somam-se a isso os docentes William Thomas e Albion Small, do mesmo departamento, que instauram um projeto voltado ao estudo empírico da vida social em Chicago, o que conversa muito com a proposta da obra "Da divisão do trabalho social" de Durkheim (2008), evidenciando mais uma aproximação do trabalho do sociólogo com os fundamentos do movimento da Escola Sociológica de Chicago.

Outra influência no movimento da Escola Sociológica de Chicago veio do viés marxista da Escola de Frankfurt. Guardadas as devidas distinções, o contexto mundial de globalização, evidenciado pela cultura de massa e pela forte onda imigratória mundial, possibilitou a expansão de pesquisas sobre seus impactos no campo sociológico. Nesse sentido, a crítica à industria cultural e ao avanço do capitalismo e suas consequências sociais evidencia-se na Escola de Frankfurt e reverbera na Escola de Chicago por meio dos seus estudos voltados às minorias sociais.

Sendo assim, é possível afirmar que o contexto de reflexão e de produção das ciências sociais da Escola Sociológica de Chicago serviu de força potencializadora para a Biblioteconomia. Nessa área, é possível identificar, nas ações e reflexões de autores como Butler, Asheim e Shera, uma relação direta com o pragmatismo de Dewey e com o método sociológico de Durkheim, e, de forma indireta, mas fundamental, a reverberação da crítica marxista que ecoou no século XX a partir dos autores da Escola de Frankfurt. Consequentemente, não é exagero relacionar essas correntes epistemológicas com o processo de constituição da própria Ciência da Informação, da qual a Biblioteconomia é parte constituinte, como bem pontua Saracevic (1996).

\title{
Procedimentos Metodológicos
}

Esta pesquisa pode ser caracterizada como qualitativa e exploratória (Minayo; Deslandes; Gomes, 2013), do tipo bibliográfica (Lira, 2014), sem delimitação cronológica, pois objetivou verificar a influência da Escola de Chicago na produção científica nacional em Ciência da Informação. 
Para identificar a produção científica brasileira em Ciência da Informação que versa sobre a Escola de Chicago e suas temáticas, foram utilizadas com fonte para a coleta de dados as publicações indexadas na seguintes bases de dados: (a) Base de Dados Referencial de Artigos de Periódicos em Ciência da Informação (Brapci), pois se acredita que referida base retrata o que se publica nacionalmente na área da Ciência da Informação; (b) Red de Revistas Científicas de América Latina y el Caribe, España y Portugal (Redalyc), considerando a possibilidade de pesquisadores brasileiros publicarem em âmbito internacional; (c) Library and Information Science Abstracts (LISA), dada a extensa cobertura da base.

A coleta dos dados foi realizada durante o segundo semestre de 2018 e não foi delimitado um limite cronológico para o filtro dos artigos recuperados; além disso, em cada base foi preciso estabelecer uma estratégia de busca específica. Na Brapci, as strings utilizadas foram “Pierce Butler", "Lester Asheim”," "Jesse Shera”, "Epistemologia Social" e "Censura". O filtro aplicado nessas buscas foi o de "Palavras-chave"; porém, no termo "Censura", também se verificou o título, o resumo e as palavras-chave denominadas pelo autor do documento, restringindo-se aos trabalhos relacionados às unidades de informação, dada a abrangência do termo.

Na Redalyc, mantiveram-se as strings consultadas na Brapci com o acréscimo de "Censura AND Bibliotec*". Para esta base, o filtro utilizado foi "artigos de Ciência da Informação"; além disso, verificaram-se as instituições dos autores, restringindo-se apenas às instituições brasileiras, considerando que este estudo está focado na produção científica nacional.

Já na LISA, as strings utilizadas foram: "Pierce AND Butler", "Jesse" AND "Shera", "Epistemology" AND "Social", "Epistemologia" AND "Social", "Censura" AND "Bibliotec*", "Censura" AND "Biblioteconomia", "Censura" AND "Livros", "Censorship" AND "Librar*", "Censorship" AND "Librarianship", "Censorship" AND "Library Science". Também foram aplicados como filtro: "todos os assuntos e indexação", "periódicos acadêmicos" e "revisado por pares".

No Quadro 1 é possível verificar a quantidade total de documentos recuperados nas três etapas de busca. Após a exclusão das duplicatas, o resultado da coleta de dados originou um montante de 25 documentos.

Estes documentos passaram por um processo de leitura transversal que permitiu classificá-los conforme a Classificação JITA. De acordo com Café e Barros (2016, p. 110), a Classificação JITA é "um esquema de classificação da área de Ciência da Informação (CI) utilizado pelo repositório internacional E-Lis". Para este artigo, foram utilizadas apenas as grandes classes que são: "Teorética e Generalidades," "Funcionalidades orientadas ao usuário, de direção e de gerenciamento", e "Objetos, aspectos pragmáticos, aspectos técnicos".

A partir da classificação dos artigos foi possível identificar em quais subáreas da Ciência da Informação os recursos teórico-metodológicos da Escola de Chicago foram mais utilizados, o que permitiiu uma reflexão sobre as mencionadas subáreas. Sendo assim, na seção seguinte serão apresentadas as reflexões acerca da influência do movimento da Escola de Chicago nas publicações científicas nacionais da área.

Quadro 1. Número de documentos recuperados e selecionados para a pesquisa.

\begin{tabular}{|c|c|c|}
\hline Termos de Busca & Documentos Recuperados & Documentos Selecionados \\
\hline Pierce Butler & 5 & 1 \\
\hline Lester Asheim & 0 & 0 \\
\hline Jesse Shera & 28 & 10 \\
\hline Epistemologia Social & 56 & 12 \\
\hline Censura & 259 & 8 \\
\hline Duplicatas & & 6 \\
\hline Corpus Final & & 25 \\
\hline Total & 320 & 31 \\
\hline
\end{tabular}

Fonte: Elaborada pelos autores (2018). 


\section{Resultados e Discussão}

A não delimitação cronológica permitiu verificar a partir de quando as temáticas relacionadas ao movimento da Escola de Chicago fazem-se presentes na produção científica brasileira, em Ciência da Informação. Esse dado é importante para mostrar dois aspectos: (a) Quantidade diminuta de artigos publicados por brasileiros sobre a temática: apenas 25 artigos recuperados em um intervalo de tempo de 31 anos; (b) Atualidade da temática na área: embora o primeiro artigo recuperado seja de 1987, todos os outros foram publicados a partir de 2004 (Figura 1).

Observa-se que a produção é quase nula até 2004, mas que, a partir deste ano, ocorre uma regularidade na produção, mesmo havendo altos e baixos. A partir dos anos 2000, percebe-se que há um retorno à discussão acerca da Epistemologia Social fomentado pelo debate sobre a história e a epistemologia na área da Ciência da Informação. Exemplos disso são os artigos de Capurro (2003) e Oddone (2007), que atualizam o campo epistemológico da área, que foi pensado, primeiramente, para a Biblioteconomia na década de 1970 e que continua na Ciência da Informação do Século XXI.

Já do ponto de vista do impacto destes artigos na comunicação científica da área, é importante destacar que 19 artigos do corpus foram publicados em periódicos com extratos entre A1 e A2, segundo a última avaliação do Qualis-Periódicos, estabelecida pela Coordenação de Aperfeiçoamento de Pessoal de Nível Superior (CAPES), na área de Comunicação e Informação. Exceção deve ser feita ao periódico Library Trends, que não figurou na última avaliação do qualis capes, sendo utilizado, neste caso, a avaliação do triênio 2010-2012 (Quadro 2).

Isso mostra que a discussão das temáticas relacionadas à Escola de Chicago dá-se em revistas com grande visibilidade e prestígio no cenário da produção científica brasileira em Ciência da Informação. Com isso, temas

\section{Quantidade de publicações por ano}

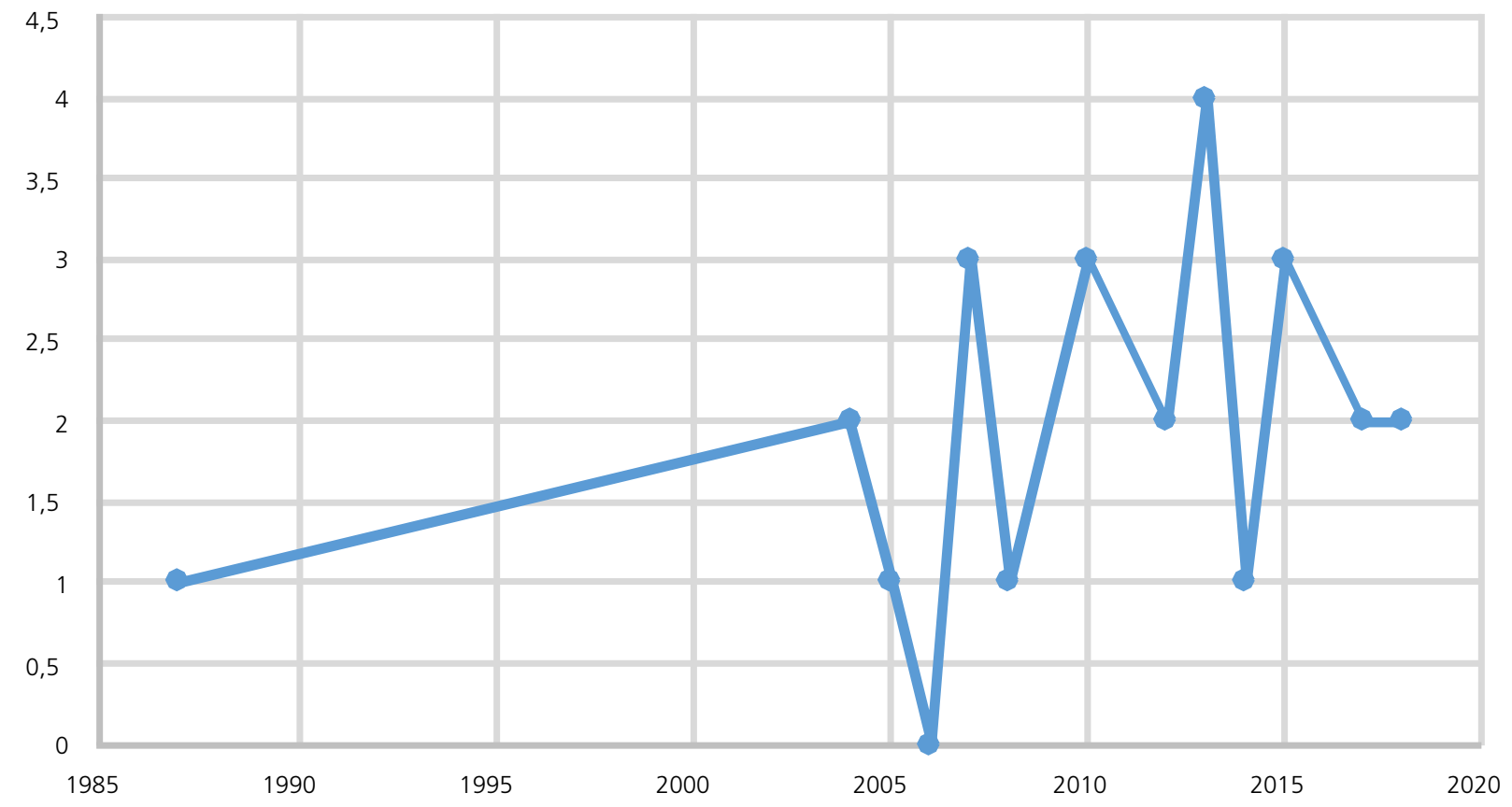

Figura 1. Corpus de análise de acordo com quantidade de publicações por ano. Fonte: Elaborada pelos autores (2018). 
Quadro 2. Periódicos recuperados como corpus de pesquisa e seu respectivo Qualis.

voltados ao movimento estudado podem suscitar novas discussões, além de possibilitar a realização de pesquisas correlatas que venham a contribuir para o avanço da área como um todo. Dos artigos publicados em períodicos com outros extratos, é importante frisar que quatro estão em revistas de extrato "B1" (Ciência da Informação: dois artigos; Revista Ibero-Americana de Ciência da Informação: um artigo; Brazilian Journal of Information Science: um artigo) e dois em estrato "B2" (ambos na Revista ACB).

Durante a leitura dos 25 documentos recuperados pelo corpus, buscaram-se referências diretas ao movimento da Escola de Chicago, tanto no texto quanto nas referências dos artigos, além da menção a Butler, Asheim e Shera, e a discussão das temáticas trabalhadas pelos pesquisadores mencionados. Também se verificou a presença de temas como Biblioteconomia enquanto ciência, censura e coleções em bibliotecas, e Epistemologia Social, que figuram entre os principais assuntos relacionados à Escola de Chicago na Biblioteconomia e na Ciência da Informação.

A análise dos textos evidenciou que grande parte dos documentos aproxima-se das contribuições deixadas pelo movimento por meio da discussão teórica. Ao todo, foram 16 artigos classificados enquanto "Teorética e Generalidades". Nesta classe, o foco dos textos está na discurso sobre os aspectos teóricos e gerais das bibliotecas e da informação, além da Sociologia da Informação e de seu uso.

Na sequência, com seis artigos classificados, está a classe "Funcionalidades orientadas ao usuário, de direção e de gerencialmento". Esta classe é demarcada por temáticas, como usuários e seus níveis de instrução e de leitura, coleções físicas de bibliotecas, publicações e questões legais, gestão, formação do profissional e a profissão em si.

Por fim, a classe "Objetos, aspectos pragmáticos, aspectos técnicos" teve apenas três documentos classificados. Nesta categoria encontram-se questões mais específicas da área, como fontes de informação, canais de informação, tratamento e serviços informacionais, serviços técnicos (em arquivos, bibliotecas e museus), tecnologias da informação e da biblioteca e técnicas de armazenamento.

A vertente pragmatista da Escola de Chicago anseia por dar utilidade às unidades de informação de modo que estas façam a diferença em seu contexto social. Entretanto, os principais expoentes da Biblioteconomia relacionados ao movimento (Butler, Shera e Asheim) dialogavam de forma teórica, expondo suas perspectivas, ao invés de suscitar discussões de cunho prático; ademais, no contexto atual, a produção científica nacional em Ciência da Informação ainda se utiliza da teorética para abordar estes mesmos temas.

As análises demonstram também que alguns textos destacam-se por estabelecer relações mais profundas com os pesquisadores da Escola de Chicago e com o próprio movimento em si. Sales (2004), por exemplo, busca estabelecer um diálogo entre as vertentes teóricas de John Dewey na área da Educação com a Biblioteca Escolar. Embora a discussão do artigo aconteça na área da teorética, o discurso de Sales (2004) permite identificar a 
presença da perspectiva pragmatista proveniente da Escola de Chicago, já que o foco do texto está na atuação bibliotecária neste tipo de unidade, de modo a tornar a Biblioteca Escolar um ambiente ativo para sua comunidade, útil enquanto unidade de informação.

De maneira geral, percebe-se que as discussões relacionadas ao movimento da Escola de Chicago giram em torno da proposta de Shera sobre a Epistemologia Social. A emergência deste autor e de sua obra, no tocante aos aspectos teóricos e epistemológicos da Cl na produção científica nacional, deve-se, em parte, à publicação de Capurro (2003). Ao definir os campos paradigmáticos da Ciência da Informação em físico, cognitivo e social, Capurro (2003) destaca Shera como um dos expoentes do último campo, sendo a proposta da disciplina de Epistemologia Social uma propulsora do terceiro e atual paradigma da Ciência da Informação, o social. Em geral, percebe-se que a relação entre o texto de Capurro e a discussão em torno da Epistemologia Social de Shera (1977) visa constituir um percurso histórico da relação entre Biblioteconomia e a Ciência da Informação no âmbito das Ciências Sociais. No corpus analisado, esse diálogo entre a Ciência da Informação e as Ciências Sociais é potencializado por autores como Renault e Martins (2007) e Alvares e Araújo Júnior (2010), que mencionam explicitamente a contribuição da Escola de Chicago no processo construtivo da Ciência da Informação.

Já no âmbito constitutivo do próprio movimento, Carvalho Silva (2013) destaca a vertente sociológica da Escola de Chicago, evidenciando a contribuição de Durkheim nas pesquisas feitas por Butler e Shera. Carvalho Silva (2013) ainda ressalta que estes pesquisadores constituem o berço do movimento da Escola de Chicago a partir do que desenvolveram durante sua atuação na Graduate Library School.

Os artigos analisados nesta pesquisa também destacam pontualmente alguns dos feitos de Butler, Shera e Asheim. Nesse sentido, Renault e Martins (2007) indicam que:

Naquele ano [1949], Shera e sua colaboradora Margaret Egan adotaram o termo 'controle bibliográfico' para se referir à documentação. Em 1951, eles passaram a utilizar a nomenclatura 'organização bibliográfica', como resposta às pressões daqueles que consideravam a conotação de censura na palavra 'controle' (Renault; Martins, 2007, p. 136).

O curioso neste trecho é que, em 1951, Shera e Egan teriam mudado o termo para evitar possíveis confusões entre o conceito de censura e "controle bibliográfico". Isso ocorreu devido à publicação de "Not censorship, but selection", de Asheim (1954), a qual defende a constituição de coleções sem a existência de uma censura institucional ou de juízo de valor dos bibliotecários. Com isso, pode-se perceber que existiu um debate, por parte da Escola de Chicago, sobre a questão da censura nas atividades biblioteconômicas a ponto de se trocar o termo "controle bibliográfico" para "organização bibliográfica". Além disso, a Epistemologia Social é considerada por Renault e Martins (2007) como uma contribuição importante nas discussões teóricas da Biblioteconomia, corroborando, portanto, com aquilo que Butler tentou fazer na década de 1930, quando propôs uma Biblioteconomia com caráter científico (Butler, 1971).

Ainda no tocante à produção nacional, encontra-se também a defesa de que as bibliotecas devem ser acessíveis e úteis à promoção da liberdade de pensamento e formação cidadã da sociedade. Essa concepção atual e universal foi bastante difundidida na Escola de Chicago, como ressalta Araújo (2014). Um exemplo da Escola de Chicago que tem relação direta com essa defesa foi, justamente, a discussão acerca da censura dos acervos e o debate sobre políticas que democratizassem o acesso aos livros.

Já em 1987, Vergueiro não só debate sobre a importância da diferença entre censura e seleção, por parte do bibliotecário, como ressalta explicitamente a contribuição de Lester Asheim para o desenvolvimento das pesquisas nesta área. Para Vergueiro (1987, p. 25), Asheim pode ser visto como "um clássico da literatura biblioteconômica [...] diferenciando seleção e censura, onde, resumidamente, o autor procura traçar duas posturas distintas: de um lado a do censor, [...] e, de outro lado, o bibliotecário em sua atividade de seleção [...]". 
No artigo, Vergueiro (1987) ressalta que não se debatia muito sobre a temática de censura e liberdade intelectual até os fins da década de 1930. Desse dado depreende-se que foi a partir da Escola de Chicago que se começou a discutir este tipo de temática na Biblioteconomia, no contexto americano. O autor ainda chama a atenção para a possibilidade de os estudos brasileiros de Biblioteconomia utilizarem-se dos exemplos norte-americanos para promover o crescimento científico da área de Biblioteconomia no Brasil. Vergueiro (1987) compreende a crítica à censura como um legado da Escola de Chicago para a Biblioteconomia, caracterizando, portanto, uma das contribuições teórico-metodológicas do movimento à Biblioteconomia e Ciência da Informação.

A literatura norte-americana que discutiu o conceito de censura na formação de coleções das bibliotecas fez parte de um debate maior sobre o que passou a ser denominado "desenvolvimento de coleções". Ao estudar as origens dos fundamentos contemporâneos desta importante área da Biblioteconomia, Weitzel (2012) destaca a contribuição norte-americana:

A literatura especializada, notadamente norte-americana, atribuiu como marco dessa nova abordagem os estudos desenvolvidos nos Estados Unidos na década de 1960. [...] O termo desenvolvimento de coleções foi, a partir desse momento, consagrado pela literatura especializada para designar os processos e as políticas que envolvem ações em relação às coleções (Weitzel, 2012, p. 181).

Pela leitura dos documentos, além destes apresentados, o artigo de Aranalde (2005) é outro exemplo que dialoga com muita proximidade com o pragmatismo da Escola de Chicago, mesmo sem fazer menção direta ao movimento. Tal artigo chama a atenção para a necessidade da ética na atuação do bibliotecário e para a importância de uma prática pautada no aspecto social da área. Além disso, discorre sobre a necessidade de consciência, por parte do bibliotecário, do "por que fazer", ou seja, saber o porquê de determinada prática de modo a torná-la útil à sociedade.

Essa necessidade de se compreender os motivos da prática e tentar fazê-la de modo útil à sociedade é, justamente, a visão pragmatista difundida pela Escola de Chicago. Aranalde (2005) menciona também o conceito de "responsabilidade social", que hoje é denominado pela área como "responsabilidade social bibliotecária" (RSB). Este termo se relaciona de forma direta com o movimento da Escola de Chicago (Moraes, 2018), uma vez que busca estabelecer diálogos entre os profissionais para fomentar ações que, de alguma forma, contribuam para a comunidade na qual a unidade de informação está inserida.

Todavia, percebe-se que, embora sejam identificadas as contribuições teórico-metodológicas da Escola de Chicago para a Ciência da Informação nos textos lidos, essa relação com o movimento não está explicita. Dentre os 25 documentos analisados, apenas três mencionam explicitamente o movimento da Escola de Chicago, sendo eles: Alvares e Araújo Júnior (2010); Vieira, Lucas e Araujo (2017) e Vieira e Lucas (2018). Outros três fazem menção à Universidade de Chicago: Oddone (2007); Araújo et al. (2010) e Correia e Zandonade (2018). Verifica-se, portanto, que os autores do corpus não mencionam o movimento da Escola de Chicago, mesmo que seu texto esteja pautado em suas perspectivas teórico-metodológicas ou em autores reconhecidos como membros do movimento.

Percebe-se também que, embora alguns textos como os de Aranalde (2005) e Weitzel (2012) abordem a necessidade de uma aproximação com a prática, as discussões deram-se em sua maioria no campo teórico, mais voltados à pesquisa básica e exploratória. Dentre os textos lidos, talvez um dos autores que mais tenha se aproximado da proposta pragmatista da Escola de Chicago tenha sido Vergueiro, por ter desenvolvido estudos voltados à área de desenvolvimento de coleções tomando Asheim como referência (Andrade; Vergueiro, 1996; Vergueiro, 2002; 2010).

Dentre os pesquisadores identificados como principais expoentes do movimento da Escola de Chicago para a Biblioteconomia e, posteriormente, para a Ciência da Informação, o reconhecimento maior ocorre com Jesse 
Shera, especialmente acerca de sua teoria da Epistemologia Social. O trabalho de Butler ainda é muito relacionado à Biblioteconomia brasileira em seu momento de origem e consolidação, conforme ressalta Souza (2009).

Todavia, a abordagem pragmatista e a perspectiva social, provenientes da vertente humanística reforçada pela Escola de Chicago, também se encontram diluídas na produção científica nacional da área. Nesse sentido, vêse que a desinformação sobre o movimento acaba, por vezes, ocultando o crédito que deveria ser dado à Escola de Chicago e aos seus membros não tão conhecidos como Butler e Asheim, por exemplo, que contribuíram para o desenvolvimento da Biblioteconomia norte-americana. Além disso, a falta de reflexão sobre os lugares e os contextos históricos do movimento segrega o trabalho de pesquisadoras como Margaret Egan, que é co-autora na formulação da Epistemologia Social, muitas vezes creditada apenas à Jesse Shera.

No entanto, é necessário estabelecer que, em termos de produção bibliográfica, de fato é Jesse Shera a quem se dá maior visibilidade ao movimento. Espera-se a continuidade de estudos onde se possa elencar, discutire homenagear outros personagens importantes da Biblioteconomia estadunidense, tais como Butler, Asheim, Egan, entre outros. Este esforço, aliado a uma base sociológica e pragmatista, deixou contribuições notáveis ao que se tem hoje, no Brasil, enquanto Ciência da Informação e que, como verificado, concentra-se mais na discussão teórica da área.

\section{Considerações Finais}

A Ciência da Informação constitui-se a partir de uma vertente teórica-metodológica e interdiscplinar, identificando-se de maneira transversal com múltiplos diálogos técnico-científicos, conforme aponta Carvalho Silva (2016) e é essa característica que ocasiona a ocorrência de aproximações profícuas e contínuas entre Biblioteconomia e Ciência da Informação no contexto brasileiro.

Todavia, no contexto norte-americano, o campo epistemológico não é interdependente. Com isso, é comum o uso do termo "Library and Information Science". Estas aproximações permitem concluir que uma contribuiu com a outra durante todo o seu processo formativo até os dias de hoje, tendo a presente pesquisa focalizado um ponto específico: o movimento intelectual da Escola de Chicago.

A Escola de Chicago foi um movimento intelectual, originado nas décadas de 1920 e 1930, tendo como ponto de partida os estudos desenvolvidos por pesquisadores que foram vinculados, em algum momento, ao Departamento de Sociologia da Universidade de Chicago. No entanto, as pesquisas destes profissionais foram ganhando corpo fora das instituições e, aos poucos, outras áreas aderiram às pesquisas empíricas e à vertente pragmatista difundida pelo Departamento.

Desde o início desta pesquisa, os dados primários evidenciavam a menção do movimento pela produção científica brasileira de maneira superficial. Foi possível perceber que as temáticas discutidas pelo movimento da Escola de Chicago possuem uma densa discussão teórica, no entanto, há um esforço, por parte dos pesquisadores, de relacionar a teoria com a prática, caracterizando a vertente pragmatista da Escola de Chicago, quando de sua preocupação de desenvolver teorias que tornassem as unidades de informação úteis para a sociedade.

Com relação às subáreas da $\mathrm{Cl}$ mais influenciadas pelas contribuições teórico-metodológicas da Escola de Chicago, com base na classificação JITA, percebeu-se que os estudos de caráter geral, voltados a "Teorética e Generalidades", obtiveram um maior número de artigos categorizados. Na sequência, a segunda subárea influenciada pelo movimento é de nível intermediário, denominada "Funcionalidades orientadas ao usuário, de direção e de gerenciamento".

Por fim, embora o nível específico da classificação JITA traga como tema os aspectos pragmatistas, os itens englobados por esta subárea são mais voltados ao fazer técnico. Mesmo o movimento da Escola de Chicago 
tendo como base o pragmatismo, as contribuições dos pesquisadores aqui elencados - Butler, Asheim e Shera -, seguem muito mais uma vertente teórica e uma discussão sobre a prática do que o estudo das técnicas sem um posicionamento crítico como pano de fundo. Este distanciamento do fazer técnico pura e simplesmente com o foco na própria técnica é característico da vertente humanística que circunda o movimento.

Durante a realização deste estudo, notou-se que muitas das contribuições teórico-metodológicas da Escola de Chicago são mencionadas na produção científica nacional em Ciência da Informação, mas, em alguns casos, dáse de forma inconsciente, reafirmando que, por vezes, sua história ou seus "começos" são desconhecidos.

Entende-se que os resultados obtidos beneficiam os pesquisadores da Ciência da Informação voltados aos estudos históricos e epistemológicos da área, já que enriquece a produção científica nacional acerca do tema, e permite que novos estudos sejam realizados a partir dessa temática. Além disso, os resultados aqui apresentados constituem possibilidades de outros estudos que versam sobre a influência do movimento nos estudos de usuários, de desenvolvimento de coleções, da organização e representação da informação e dos usos sociais da tecnologia na gestão da informação em bibliotecas, arquivos e museus.

Como sugestão para estudos futuros, o presente estudo indica a possibilidade de investigação sobre a Graduate Library School da Universidade de Chicago e as publicações vinculadas à American Library Association, além da análise do próprio movimento associativo e do trabalho de outros pesquisadores notórios da área da Biblioteconomia ou da Ciência da Informação, cujas contribuições ainda não foram alvo de pesquisa e produção científica da área.

\section{Colaboradores}

K. R. Vieira colaborou na concepção, coleta e análise de dados e redação do artigo. C. Karpinski colaborou na concepção, na análise de dados, na redação e na revisão do artigo.

\section{Referências}

Alvares, L.; Araújo Junior, R. H. Marcos históricos da ciência da informação: breve cronologia dos pioneiros, das obras clássicas e dos eventos fundamentais. Transinformação, v. 22, n. 3, p. 195-205, 2010. Disponível em: http://www.scielo.br/ pdf/tinf/v22n3/a01v22n3.pdf. Acesso em: 14 jan. 2019.

Andrade, D.; Vergueiro, W. Aquisição de materiais de informação. Brasília: Briquet de Lemos, 1996. 118 p.

Aranalde, M. M. A questão ética na atuação do profissional bibliotecário. Em Questão, v. 11, n. 2, p. 337-368, 2005. Disponível em: https://seer.ufrgs.br/EmQuestao/article/view/124/ 82. Acesso em: 16 jan. 2019.

Araújo, C. A. A. Arquivologia, Biblioteconomia, Museologia e Ciência da Informação: o diálogo possível. Brasília: Briquet de Lemos, 2014. 200 p.

Araújo, C. A. A. O sujeito informacional no cruzamento da Ciência da Informação com as Ciências Humanas e Sociais. In: Encontro Nacional de Pesquisa em Ciência da Informação, 14., 2013, Florianópolis. Anais eletrônicos [...]. Florianópolis: Brapci, 2013. Disponível em: http://www.brapci.inf.br/index.php/ article/download/40403. Acesso em: 14 jan. 2019.

Araújo, C. A. A. et al. A contribuição de J. H. Shera para a Ciência da Informação no Brasil. Revista $A C B$, v. 15, n. 2, p.
71-89, 2010. Disponível em: https://revista.acbsc.org.br/racb/ article/view/712/pdf_35. Acesso em: 14 jan. 2019.

Asheim, L. Not censorship but selection. Wilson Library Bulletin, v. 28, p. 63-67, 1954. Copy of published article by American Library Association, at 2005, under authorization of Michael Frank. Available from: http://www.ala.org/advocacy/ intfreedom/NotCensorshipButSelection. Cited: Jan. 142019.

Becker, H. A Escola de Chicago. Mana, v. 2, n. 2, p. 177-188, 1996. Disponível em: http://www.scielo.br/scielo.php?script= sci_arttext\&pid=S0104-93131996000200008\&lng=en\&nrm=i so. Acesso em: 16 jan. 2019.

Butler, P. Introdução a ciência da biblioteconomia. Rio de Janeiro: Lidador, 1971. 86 p.

Café, L. M. A.; Barros, C. M. Panorama da produção nacional e internacional sobre informação musical. Informação e Sociedade, v. 26, n. 2, p.107-119, 2016. Disponível em: http://www.periodicos.ufpb.br/ojs/index.php/ies/article/ view/28484/16208. Acesso em: 15 jan. 2019.

Capurro, R. Epistemologia e ciência da informação. In: Encontro Nacional de Pesquisa em Ciência da Informação, 5., 2003, Belo Horizonte. Anais eletrônicos [...]. Belo Horizonte: Associação Nacional de Pesquisa e Pós-Graduação em 
Ciência da Informação e Biblioteconomia, 2003. Disponível em: http://www.capurro.de/enancib_p.htm. Acesso em: 16 jan. 2019.

Carvalho Silva, J. L. Normatividade, tecnicidade e/ou cientificidade da Biblioteconomia. Transinformação, v. 25, n. 1, p. 5-17, 2013. Disponível em: http://www.scielo.br/pdf/tinf/ v25n1/a01v25n1.pdf. Acesso em: 14 jan. 2019.

Carvalho Silva, J. L. Tópicos em biblioteconomia e ciência da informação: epistemologia, política e educação. Rio de Janeiro: Agência Biblioo, 2016. 124 p.

Correia, M. C. S.; Zandonade, T. O conceito de informação como conhecimento registrado. Revista Ibero-Americana de Ciência da Informação, n. 1, v. 11, p. 83-102, 2018. Disponível em: http://www.brapci.inf.br/index.php/res/download/89556. Acesso em: 16 jan. 2019.

Durkheim, E. Da divisão do trabalho social. 3. ed. São Paulo: Martins Fontes, 2008. 483 p.

Eufrasio, M. A. A formação da Escola Sociológica de Chicago. Plural, v. 2, p. 37-60, 1995. Disponível em: http://www.revistas. usp.br/plural/article/view/68042/70612. Acesso em: 14 jan. 2019.

Figueiredo, N. M. Aspectos especiais de estudos de usuários. Ciência da Informação, v. 12, n. 2, p. 43-57, 1983. Disponível em: http://revista.ibict.br/ciinf/article/view/184/184. Acesso em: 14 jan. 2019.

Francelin, M. M. Epistemologia da Ciência da Informação: evolução da pesquisa e suas bases referenciais. Perspectivas em Ciência da Informação, v. 23, n. 2, p. 89-103, 2018. http:// dx.doi.org/10.1590/1981-5344/3135

Ghiraldelli Junior, P. O que é pragmatismo. São Paulo: Brasiliense, 2007. 145 p. (Primeiros Passos, 323).

Guimarães, J. A. C. A dimensão teórica do tratamento temático da informação e suas interlocuções com o universo científico da International Society for Knowledge Organization (ISKO). Revista Ibero-Americana de Ciência da Informação, v. 1, n. 1, 2008. Disponível em: http://www.brapci.inf.br/ index.php/ article/download/51152. Acesso em: 14 jan. 2019.

Lankes, D. Expect more: demanding better libraries for today's complex world. David Lankes, Columbia, 2013. Available from: https://davidlankes.org/new-librarianship/expect-moredemanding-better-libraries-for-todays-complex-world/1the-arab-spring-expect-the-exceptional/1-a-primaveraarabe-espere-o-excepcional/. Cited: Jan. 142019.

Lira, B. C. O passo a passo do trabalho científico. 2. ed. Petrópolis: Vozes, 2014.

Matos, M. T. N. B. A evolução dos arquivos e do conhecimento em arquivologia. Revista Ibero-Americana de Ciência da Informação, v. 5, n. 2, p. 19-28, 2012. Disponível em: http:// periodicos.unb.br/index.php/RICl/article/view/1688/1486. Acesso em: 14 jan. 2019.

Minayo, M. C. S.; Deslandes, S. F.; Gomes, R. Pesquisa social: teoria, método e criatividade. 33. ed. Petrópolis: Vozes, 2013. $108 \mathrm{p}$.

Moraes, M. B. Responsabilidade social bibliotecária (RSB): o que significa em tempos de rupturas democráticas? In: Spudeit, D. F. A. O.; Moraes, M. B. (org.). Biblioteconomia social: epistemologia transgressora para o Século XX. São Paulo: Abecin Editora, 2018. p. 49-76. Disponível em: http://abecin. org.br/data/documents/E-Book_Biblioteconomia_Social.pdf. Acesso em: 16 jan. 2019.

Oddone, N. Revisitando a "epistemologia social": esboço de uma ecologia sociotécnica do trabalho intelectual. Ciência da Informação, v. 36, n. 1, p. 108-123, 2007. Disponível em: http://www.scielo.br/pdf/ci/v36n1/a08v36n1.pdf. Acesso em: 16 jan. 2019.

Ortega Y Gasset, J. Misión del bibliotecario. 2. ed. Madrid: Revista de Occidente, 1967. 83 p.

Renault, L. V.; Martins, R. O retrato da ciência da informação: uma análise de seus fundamentos sociais. Encontros Bibli, v. 12, n. 23, p. 133-150, 2007. Disponível em: https:// periodicos.ufsc.br/index.php/eb/article/view/15182924.2007v12n23p133/400. Acesso em: 14 jan. 2019.

Sales, F. O ambiente escolar e a atuação bibliotecária: o olhar da educação e o olhar da biblioteconomia. Encontros Bibli, v. 9, n. 18, p. 40-57, 2004. Disponível em: https://periodicos.ufsc.br/ index.php/eb/article/view/1518-2924.2004v9n18p40/5472. Acesso em: 14 jan. 2019.

Santos, A. P. L.; Rodrigues, M. E. F. Ciência da Informação: demarcação teórico-disciplinar e as interações interdisciplinares com a Biblioteconomia. Transinformação, v. 26, n. 1, p. 91-100, 2014. Disponível em: http://www.scielo.br/pdf/tinf/ v26n1/a09.pdf. Acesso em: 13 mar. 2019.

Saracevic, T. Ciência da informação: origem, evolução e relações. Perspectivas em Ciência da Informação, v. 1, n. 1, p. 41-62, 1996. Disponível em: http://portaldeperiodicos.eci. ufmg.br/ index.php/pci/article/view/235/22. Acesso em: 14 jan. 2019.

Shera, J. H. Epistemologia social, semântica geral e biblioteconomia. Ciência da Informação, v. 6, n. 1, 1977. Disponível em: http://revista.ibict.br/ciinf/article/view/92/92. Acesso em: 14 jan. 2019.

Silva, D. R. John Dewey, Walter Lippmann e Robert E. Park: diálogos sobre públicos, opinião pública e a importância da imprensa. Fronteiras, v. 18, n. 1, p. 57-68, 2016. Disponível em: http://revistas.unisinos.br/ index.php/fronteiras/article/ viewFile/fem.2016.181.06/5296. Acesso em: 14 jan. 2019.

Souza, F. C. O ensino da biblioteconomia no contexto brasileiro: século XX. 2. ed. rev. Florianópolis: Editora da UFSC, 2009. $189 \mathrm{p}$.

Vergueiro, W. C. S. Censura e seleção de materiais em bibliotecas: o despreparo dos bibliotecários brasileiros. Ciência da Informação, v. 16, n. 1, 1987. Disponível em: http://revista. ibict.br/ciinf/article/view/266/266. Acesso em: 16 jan. 2019.

Vergueiro, W. C. S. Qualidade em serviços de informação. São Paulo: Arte \& Ciência, 2002.111 p.

Vergueiro, W. C. S. Seleção de materiais de informação: princípios e técnicas. 3. ed. Brasília: Briquet de Lemos Livros, 2010. $120 \mathrm{p}$.

Vieira, K. R.; Karpinski, C. As contribuições da Escola de Chicago para a Ciência da Informação. Pesquisa Brasileira em Ciência da Informação e Biblioteconomia, v. 13, n. 1, p. 128-138. 
2018a. Disponível em: http://www.periodicos.ufpb.br/ojs/ index.php/pbcib/article/view/40189/20561. Acesso em: 14 jan. 2019

Vieira, K. R.; Karpinski, C. A Escola Sociológica de Chicago e a Ciência da Informação. In: Encontro Nacional de Pesquisa em Ciência da Informação, 19., 2018, Londrina. Anais eletrônicos [...]. Londrina: Associação Nacional de Pesquisa e Pós-Graduação em Ciência da Informação e Biblioteconomia, p. 400-408, 2018b. Disponível em: http://enancib.marilia.unesp.br/index. php/XIXENANCIB/xixenancib/paper/viewFile/846/1400. Acesso em: 14 jan. 2019.

Vieira, K. R.; Lucas, E. R. O. Jesse Shera e sua contribuição para o campo da Biblioteconomia e Ciência da Informação.
Encontros Bibli, v. 23, n. 51, p. 17-30, 2018. Disponível em: https://periodicos.ufsc.br/index.php/eb/article/view/1518-2 924.2018v23n51p17/35507. Acesso em: 14 jan. 2019.

Vieira, K. R.; Lucas, E. R. O; Araujo, A. V. F. Jesse Shera: entre citações e bibliografia. Revista ACB, v. 22, n. 2, p. 208-226, 2017. Disponível em: https://revista.acbsc.org.br/racb/article/ view/1307/pdf. Acesso em: 17 jan. 2019.

Weitzel, S. R. Desenvolvimento de coleções: origem dos fundamentos contemporâneos. Transinformação, v. 24, n. 3, p. 179-190, 2012. Disponível em: http://www.scielo.br/pdf/tinf/ v24n3/a03v24n3.pdf. Acesso em: 14 jan. 2019.

Westbrook, R. B.; Teixeira, A. John Dewey. Recife: Fundação Joaquim Nabuco, 2010. 135 p.
13 